\title{
Research on Public Private Partnerships with Privately Informed Local Governments
}

\author{
Xiao Feng \\ College of Economics, Jinan University, Guangzhou, China \\ Email: 714696908@qq.com
}

Received 29 March 2016; accepted 18 April 2016; published 21 April 2016

Copyright (C) 2016 by author and Scientific Research Publishing Inc.

This work is licensed under the Creative Commons Attribution International License (CC BY).

http://creativecommons.org/licenses/by/4.0/

c) (7) Open Access

\begin{abstract}
Based on the signaling model, this article analyzes the public private partnership contracts between local governments privately informed about the quality of the project and the private sector hired to run projects. On the one hand, the local governments know more details about features of the PPP project (such as possibility that the project will be shut down by some unfavorable policy factors in the future); on the other hand, the effort undertook by private sector in building period is uncontractable. Our results show that the local governments may design a contract which signals the quality of the project. The signaling contract, however, will reduce the agent's incentives, and create a trade-off between signaling and high-powered incentive.
\end{abstract}

\section{Keywords}

Private Public Partnerships, Signaling Game, Moral Hazard

\section{Introduction}

In China, the evolution of the PPPs does not go well all the time. There are PPP projects operated well in which the public, the government and private investors all benefit from, while there are also failed projects. To attract private investors, the privately informed local governments may promise something hard to be carried out. After investors participate, the local governments' promises cannot be fulfilled, and private investors may suffer losses. Taking Sino French Tangshan Water Plant Project in Lianjiang as an example, in 1997, the contract of the project was signed by Lianjiang Tap water Company and Sino French Water Investment Co, Ltd. When the contract was signed, the terms divorced from reality, such as high water price and purchase quantity. After Sino French Water invested a lot and built the water plant with advanced equipments, the local government refused to perform the contract under the veil of "unfair" contract, causing the vacancy of the water plant for ten years after 
the completion. Finally, the local government repurchased Sino French Tangshan Water Plant Project at a low price ${ }^{1}$.

A large number of scholars have studied about PPPs. However, to some extent, information asymmetry ex ante of the PPP projects is neglected, such as the privately informed local government. As shown in the example above, local governments may give false reports on the project prospect in the real world. As the initiator of the project, the local government may be privately informed of the PPP project, such as the future policy changes, municipal planning and financial situation. In this case, the privately informed government may seek for information rents, and initiate the projects whose investment cannot be made up. This article will analyze the PPP contracts with privately informed local governments, and study how the information advantages of the local governments influence the incentive intensity of PPP projects.

\section{Literature Review}

A mass of scholars have studied PPP. Based on the incomplete contract theory, Hart (2003) [1] studied the construction-operation binding efficiency of PPP. The main conclusion is that, assuming that the private sector's investment in the construction stage is uncontractable, if investment helps to reduce operating costs and improve service quality, the binding contract has advantage in incentive; if investment will significantly reduce the quality of service while reducing operating costs, the separated contract is more appropriate.

Martimort and Pouyet (2008) [2] discussed about the measurable (complete contract) and immeasurable (incomplete contract) performance (operating cost and asset quality). As a result, they found that the positive externality between different stages could improve the binding efficiency in both cases, so that the binding contract was better than the separated contract. The definition of "externality between different stages" is different from that of general externality. It means the behaviors of the participant in a certain stage will affect the efficiency in the later phases. Iossa and Martimort (2012) [3] discussed about PPP contracts with positive externality between stages and external impact in operation stage. They found that if information of external impact was symmetrical for both parties (whether both parties could observe the realized value of the nature or not), the binding contract was superior to the separated contract; when the external impact was private information of the private sector, the problem of information asymmetry appeared and influenced the binding efficiency, and in some situations the separated contract was superior to the binding contract.

Martimort and Pouyet (2008) [2] discussed about the collusion in the PPP projects. The governments and PPP project operators may conspire and report a wrong type of externality between different stages to the public, so that the inefficient project organization type is elected, and both parties make a profit. Iossa and Martimort (2014) [4] discussed about the PPP contract with contracting cost. When the government officials can profit from the income of the private sectors (for example, the government officials will obtain part of the income of the private sector as bribe), opportunistic government officials have more incentive to choose an incomplete contract, so that the non-optimal contract type is elected.

Bettignies and Ross (2009) [5] introduced the financial contracting theory. Private development can dominate public financing through more efficient termination decisions for bad projects, resolving soft budget constraint problems. Due to contractual incompleteness and externalities, on the other hand, private developers cannot commit to large debt repayments, and hence can finance only a subset of valuable projects. Public developers, who do not face the same commitment problems, can finance a larger set of projects.

Engel, Fischer and Galetovic (2013) [6] mainly considered the inefficiency of government subsidies. On the one hand, to raise public funds, the government needs to bear the shadow cost (such as taxation distortion on the total output). On the other hand, the defective subsidy process will produce additional costs (for example, government subsidies often require PPP operators to make some fixed investment with low efficiency). As a result, the optimal demand risk allocation contract will be characterized by the lowest income guarantee and the upper income limit. When demand is below a certain threshold, the government ensures the PPP operator's lowest income through subsidies; when the demand is higher than a certain limit, the government will take the excessive profit; when demand is between two thresholds, the PPP operator assumes all demand risks, which means it does not accept government subsidies.

As mentioned above, many scholars have studied PPP contract arrangements, such as how control right configuration (Hart, et al.), optimal binding (Martimort, et al.), corruption (Iossa, et al.), soft budget constraint

\footnotetext{
${ }^{1}$ Economic Observer News: Ten-year Dispute between a City and Sino French Water. http://www.eeo.com.cn/eeo/jigcb/2009/08/24/148934.shtml.
} 
(Bettignies, et al.) and subsidy inefficiency (Engel, et al.) influence the performance of the PPP projects. However, most scholars focus on problems after contracting, and few of them focus on how ex ante information asymmetry affects the performance of the PPP project. In developing countries such as China, PPP might be influenced by unsound legal system, changes of the policy environment of PPP, incomplete information disclosure of the government and other factors. This article will study how the information advantages of the local government affects the PPP contracting.

\section{Model}

\subsection{Assumption}

There are two participants of the PPP project: a local government $(G)$ and a private sector (P). In this article, PPP refers to public private partnerships initiated by the government, built and operated by organizations other than the government (private enterprise, SPV, etc.). Assume that the local government initiating the PPP project is privately informed. The local government has more precise information about the economic prospect, fiscal revenue and expenditure, the public's attitude towards the project, etc. At the same time, we assumes that the private sector is responsible for construction and operations of the PPP project, and the private sector's effort level during the construction and operation will affect the performance of the project. We assume that the project quality is the private information of the local government, and the effort level of the private sector is the private information of the private sector. On the one hand, Due to their own interests (such as easier to attract investment), the local government may report false prospect of project (such as better financial revenue and expenditure) to the potential investors (private sector), initiate the project whose actual value is lower than the value expected by the private sector. On the other hand, because the effort level is private information, the local government must take measures to supervise the effort level of the private sector, such as the corresponding incentive arrangement in the cooperation agreement. Based on the above conditions, the game between the two parties is as shown in Figure 1.

When $t=0$ (before contracting stage), the quality of the PPP project is as follows. $\theta \in\left\{\theta_{L}, \theta_{H}\right\}$ and $\left(\theta_{H}>\theta_{L}\right)$. When $\theta=\theta_{H}$, the project prospect is relatively good. We call such project a "good project"; otherwise, the project has a poor prospect, and we call that the project is a "bad project". When $t=1$ (the contracting stage), as the entrusting party, the government $(G)$ decides whether to initiate the PPP project, and send a take-it-or-leave-it contract to the agent P. Following researches of PPP contracting by Issoa [3] [4] and other scholars, we assume that the PPP project has "externality between stages". The agent's behavior in a stage will affect the performance of the subsequent stages. If more appropriate design is used in construction stage, in the operation stage higher (or lower) income or lower (higher) operating cost may be induced. When $t=2$ (the construction stage), the agent $\mathrm{P}$ makes efforts $e$, and bears the construction cost $I$ and effort cost $0.5 e^{2}$. When $t=3$ (in the implementation stage), the realized revenue of the project is as follows. $R=e+\theta+\varepsilon$. The two parties distribute $R$ and repay contractable investment $I$ by the private sector in accordance with the terms. We assume that realized value of revenue is observable and contractable for both parties.

For $R, e$ is the effort level of the agent when $t=1$. $\theta \in\left\{\theta_{L}, \theta_{H}\right\}$ is the project quality determined exogenously when $t=0 . \varepsilon \sim N\left(0, \sigma_{\varepsilon}^{2}\right)$ is the external shock realized when $t=2$. Effort level $e$ is not observable by G. Combined with the external shock $\varepsilon$. We can found that $\mathrm{G}$ need to provide incentive schemes to the agent to implement its targeted effort level. On the other hand, the prior probability of "good project" is $P\left(\theta_{H}\right)=p$. Its realized value is observed by $\mathrm{G}$ when $t=0$. In the whole process of the project, it is private information of $\mathrm{G}$. The above assumption for $\theta$ describes such a situation, as the initiator of the PPP project, relative to the private sector (P), G is privately informed. For example, G knows whether the PPP project has big policy risk beforehand, whether there will be competition of similar project in the future, and even whether $G$ itself has ability to perform its obligations stipulated in the contract. In this case, P may face the problem of hidden information. $\mathrm{G}$ may lie about higher project value to get profit.

In this article, we assume that the participants of PPP are risk averters, for the reason that PPP projects are

$\begin{array}{cccc}\mathrm{t}=0 & \mathrm{t}=1 & \text { P bears the cost } I & \mathrm{t}=3 \\ \theta \text { is realized } & \text { Contracting } & \text { and makes efforts } & R \text { is realized }\end{array}$


usually infrastructure projects and huge investments are required, such as subway, highway, airport, schools, etc. We can believe that the project will occupy a significant share of funds of P. In the model, G is the local government with limited ability, whose financial budget can’t afford a great number of PPP projects. So the PPP project is "important" enough for both parties. The utility function of each party is CARA utility function like $V(w)=-\exp (-\delta w)$. The risk aversion coefficient of $\mathrm{G}$ is $\gamma$, and the risk aversion coefficient of $\mathrm{P}$ is $\lambda$ $(\gamma, \lambda>0)$. At the same time, according with convention of moral hazard models, we specify that all feasible contracts shall be took the form of $r(\theta, e)=\alpha(\theta, e)+\beta(\theta, e) R \quad(\beta \in[0,1])$. When $t=3$ (the distribution of $\mathrm{R})$, the private sector obtain $r+I$, and $\mathrm{G}$ obtain $R-r-I$.

\subsection{Contract Arrangement When the Project Quality Is Public Knowledge}

Before we research on the situation that local government is privately informed (project quality $\theta$ is the private information of the local government), we should first consider the situation that the project type is common knowledge of both parties (information symmetry). It will be the baseline. As $\theta$ is contractable and effort level $e$ is uncontractable, there is problem of moral hazard. The local government will offer incentives schemes for the private sector through the PPP contract design. It can be expected that incentive and risk sharing will affect the contract design. At this time, the optimal problem of $\mathrm{P}$ is as follows.

$$
U_{P M}(\theta)=\underset{e}{\operatorname{Max}} \alpha(\theta)+\beta(\theta)(\theta+e(\theta))-\frac{1}{2} \lambda \beta^{2}(\theta) \sigma_{\varepsilon}^{2}-\frac{1}{2} e^{2}
$$

When $e$ is uncontractable, in $t=2 \mathrm{P}$ determines the optimal effort level. Each unit of effort level of P can only get $\beta<1$ unit as income. From Equation (1), we can obtain $e(\theta)=\beta(\theta)$. As P's distribution proportion of $R$ rises, the private sector tends to have a higher effort level in the construction stage. At this time, the optimal problem of $\mathrm{G}$ is as follows.

$$
\begin{array}{ll}
U_{G M} & (\theta)=\underset{\alpha, \beta, e}{\operatorname{Max}}(1-\beta(\theta))(\theta+e)-\frac{1}{2} \gamma(1-\beta(\theta))^{2} \sigma_{\varepsilon}^{2}-\alpha(\theta) \\
\text { s.t. } \quad & U_{P M}(\theta) \geq 0 \\
& e(\theta)=\beta(\theta)
\end{array}
$$

To solve the optimization problem of the principal, we can get the following proposition.

Proposition 1. When $\theta$ is contractable and $\boldsymbol{e}$ is uncontractable, equilibrium effort level $\left(e_{M i}\right)(i=L, H)$ is as follow.

$$
e_{M i}=\beta^{*}=\frac{1+\gamma \sigma_{\varepsilon}^{2}}{1+\gamma \sigma_{\varepsilon}^{2}+\lambda \sigma_{\varepsilon}^{2}}
$$

$e_{\mathrm{Mi}}=\beta^{*}$. When the effort level is unobservable, it is efficient to $\mathrm{P}$ to assume part of the risks. The increase of variable income proportion $(\beta)$ will lead to higher level of effort. By partial derivative, we can obtain $\partial e_{M i} / \partial \sigma_{\varepsilon}^{2}=\partial \beta^{*} / \partial \sigma_{\varepsilon}^{2}<0, \lim _{\sigma_{\varepsilon}^{2} \rightarrow+\infty} \beta=\gamma /(\gamma+\lambda)$ and $\lim _{\sigma_{\varepsilon}^{2} \rightarrow 0} \beta=1$. Participants are faced with trade-off between incentive and risk sharing. With the increased risks, both parties will pay more attention to risk sharing. The distribution ratio $(\beta)$ is getting close to the optimal risk sharing proportion $(\gamma /(\gamma+\lambda))$. When $\sigma_{\varepsilon}^{2}$ is getting close to zero, the importance of risk problem declines, the PPP contract is more likely to be the incentive scheme of $e$ than a risk-sharing contract, and $\mathrm{P}$ will faced with a bigger income distribution proportion $(\beta)$. In $t=2$, the agent $P$ will face higher incentive intensity.

Finally, the incentive contract signed by both parties in the state of $\theta_{i} \quad(i=L, H)$ when $\theta$ is common knowledge is recorded as $\left(\alpha_{i}, \beta_{i}\right)$. We can obtain:

$$
\begin{gathered}
\beta_{i}=\beta\left(\theta_{i}\right)=\beta^{*} \\
\alpha_{i}=\alpha\left(\theta_{i}\right)=-\beta^{*} \theta_{i}-\frac{1}{2} \beta^{* 2}\left(1-\lambda \sigma_{\varepsilon}^{2}\right)
\end{gathered}
$$

\subsection{Contract Arrangement When the Project Quality Is Private Information of the Local Government}

In this part, we will analyze the privately informed local government. Considering the contract specified in (3) 
and (4), assume that P "believes” $\tilde{\theta}$ reported by G, then the optimization problem of G is as follows.

$$
\tilde{U}_{G M}(\theta)=\operatorname{Max}_{\tilde{\theta}} \theta-\beta^{*}(\theta-\tilde{\theta})-\frac{1}{2} \gamma \sigma_{\varepsilon}^{2}+\beta^{*}\left(1+\gamma \sigma_{\varepsilon}^{2}\right)-\frac{1}{2} \beta^{* 2}\left(1+\gamma \sigma_{\varepsilon}^{2}+\lambda \sigma_{\varepsilon}^{2}\right)
$$

It can be found that in any case G tends to report a high value $\tilde{\theta}=\theta_{H}$. That is to say, the local government always promises a more optimistic prospect of the project to private investors. When $\theta=\theta_{L}$, the privately informed $\mathrm{G}$ gets information rent $\beta^{*}\left(\theta_{H}-\theta_{L}\right)$ from $\mathrm{P}$. When $\mathrm{P}$ faces stronger incentive intensity $\beta^{*}$, it also means $\mathrm{G}$ has greater motivation to hide the bad quality of the project $\left(\theta_{L}\right)$.

At this time, the game between both parties is as follows. When $t=0, \theta \in\left\{\theta_{L}, \theta_{H}\right\}$ is realized and observed by G. When $t=1$, G decides whether to initiate the PPP project, and propose a contract $(\alpha, \beta)$ to P. According to the contract received, P updates its belief $\mu(\theta \mid \alpha, \beta)$ about $\theta$, and decides whether to participate in the PPP project. When $t=2$, agent $\mathrm{P}$ makes efforts $e$, and bears the construction cost $I$ and effort cost $0.5 e^{2}$. When $t=3$, revenue $R=e+\theta+\varepsilon$ is realized. $R$ is distributed in accordance with the contract and repay the contractable investment $I$ made by private sector.

Considering the game above, the two part is face the uncertainty of the project quality at this time, but under the established sharing proportion $\beta$, in $t=2$ the effort cost is $\frac{1}{2} e^{2}$. $\mathrm{P}$ will always get the revenue of $\beta e$ in $t$ $=3$. Therefore, we can believe that $e=\beta$ is P's subgame perfect Nash equilibrium strategy. In this case, problem can be simplified to a pure signal game. In this article, we only consider the following separating equilibrium and pooling equilibrium.

1) Separating equilibrium

From Equation (5), we have found that when $\beta_{L}=\beta_{H}$ and the project type is "bad project", the local government will choose to report the wrong type $\tilde{\theta}=\theta_{H}$; otherwise, when the project type is "good project", the local governments has no incentive to report a wrong type. Therefore, in the separating equilibrium, we believe that when $\theta=\theta_{H}$ G will deviate from the incentive contract $\left(\alpha_{H}, \beta_{H}\right)$, and send the signal of "good project" to $\mathrm{P}$ to distinguish between "good" and "bad" project.

Here, when the project is "good project", $\mathrm{G}$ issues the contract $\left(\alpha_{H}^{\prime}, \beta_{H}^{\prime}\right)$ and the posterior belief of the private sector is $\mu\left(\theta_{H} \mid \alpha_{H}^{\prime}, \beta_{H}^{\prime}\right)=1$; when the project is "bad project", $\mathrm{G}$ issues the contract $\left(\alpha_{L}^{\prime}, \beta_{L}^{\prime}\right)$, and the posterior belief is $\mu\left(\theta_{L} \mid \alpha_{L}^{\prime}, \beta_{L}^{\prime}\right)=1^{2}$. At the same time, $e(\theta)=\beta(\theta)$. When the project type is "good project", $\mathrm{G}$ has no incentive to disguise the project as "bad project", so we make:

$$
\begin{gathered}
\beta_{L}^{\prime}=\beta_{L}=\beta^{*} \\
\alpha_{L}^{\prime}=\alpha_{L}=-\beta^{*} \theta_{L}-\frac{1}{2} \beta^{* 2}\left(1-\lambda \sigma_{\varepsilon}^{2}\right)
\end{gathered}
$$

When the project type is "good project", under the separating equilibrium, the contract $\left(\alpha_{H}^{\prime}, \beta_{H}^{\prime}\right)$ must satisfy $\left(\alpha_{H}^{\prime}, \beta_{H}^{\prime}\right) \neq\left(\alpha_{L}^{\prime}, \beta_{L}^{\prime}\right)$. At the same time, the contract $\left(\alpha_{H}^{\prime}, \beta_{H}^{\prime}\right)$ must ensure that P participates in the PPP project:

$$
U_{P S}\left(\theta_{H}\right)=\alpha\left(\theta_{H}\right)+\beta\left(\theta_{H}\right) \theta_{H}-\frac{1}{2} \lambda \beta^{2}\left(\theta_{H}\right) \sigma_{\varepsilon}^{2}+\frac{1}{2} \beta^{2}\left(\theta_{H}\right) \geq 0
$$

$\alpha(\theta)=-\beta(\theta) \theta_{H}+\frac{1}{2} \lambda \beta^{2}(\theta) \sigma_{\varepsilon}^{2}-\frac{1}{2} \beta^{2}(\theta)+t(\theta)$. In which, $t\left(\theta_{H}\right) \geq 0$ and $t\left(\theta_{L}\right)=0$. When the type is $\theta$, and $\mathrm{G}$ chooses a $\hat{\theta}$ type-contract $\left(\hat{\theta} \in\left\{\theta_{H}, \theta_{L}\right\}\right)$. Its utility is $U_{G S}(\theta, \hat{\theta})$, satisfy:

$$
U_{G S}(\theta, \hat{\theta})=(1-\beta(\hat{\theta}))(\theta+\beta(\hat{\theta}))-\frac{1}{2} \gamma(1-\beta(\hat{\theta}))^{2} \sigma_{\varepsilon}^{2}-\alpha(\hat{\theta})
$$

In the separating equilibrium, G has no incentive to disguise the project as "bad project":

$$
U_{G S}\left(\theta_{L}, \theta_{L}\right) \geq U_{G S}\left(\theta_{L}, \theta_{H}\right)
$$

After solving (6), (7), (9) and (10), based on the "intuitive criterion", we only consider the minimum cost deviation. We can obtain:

${ }^{2}$ We call $\left(\alpha_{i}^{\prime}, \beta_{i}^{\prime}\right)$ separated contract. 


$$
\begin{gathered}
\beta_{H}^{\prime}=\beta^{* *}=\beta\left(\theta_{H}\right)=\frac{\theta_{H}-\theta_{L}+1+\gamma \sigma_{\varepsilon}^{2}}{1+\gamma \sigma_{\varepsilon}^{2}+\lambda \sigma_{\varepsilon}^{2}}-\sqrt{\left(\frac{\theta_{H}-\theta_{L}}{1+\gamma \sigma_{\varepsilon}^{2}+\lambda \sigma_{\varepsilon}^{2}}\right)^{2}+\frac{2\left(\theta_{H}-\theta_{L}\right)\left(1+\gamma \sigma_{\varepsilon}^{2}\right)}{\left(1+\gamma \sigma_{\varepsilon}^{2}+\lambda \sigma_{\varepsilon}^{2}\right)^{2}}} \\
\alpha_{H}^{\prime}=\alpha\left(\theta_{H}\right)=-\beta^{* *} \theta_{H}+\frac{1}{2} \lambda \beta^{* * 2} \sigma_{\varepsilon}^{2}-\frac{1}{2} \beta^{* * 2}
\end{gathered}
$$

It can found that $0<\beta^{* *}<\beta^{*}<1$. When $\beta_{H}^{\prime}=\beta^{* *}$ and $\beta_{L}^{\prime}=\beta^{*}, U_{G S}\left(\theta_{L}, \theta_{L}\right) \geq U_{G S}\left(\theta_{L}, \theta_{H}\right)$. There is no incentive to disguise the project as "bad project", so $\left(\alpha_{i}^{\prime}, \beta_{i}^{\prime}\right)$ will lead to separating equilibrium. Of course, in order to ensure that the separating equilibrium is established, we require that $\tilde{U}_{G M}\left(\theta_{L}\right) \geq I$ and $U_{G S}\left(\theta_{H}, \theta_{H}\right) \geq I$.

Proposition 2. When $\boldsymbol{\theta}$ and $\boldsymbol{e}$ are uncontractable, $\tilde{U}_{G M}\left(\theta_{L}\right) \geq I$ and $U_{G S}\left(\theta_{H}, \theta_{H}\right) \geq I$, there is the separated contract $\left(\alpha_{i}^{\prime}, \beta_{i}^{\prime}\right)$, so that the equilibrium effort level $e_{S i}(i=L, H)$ is as follows:

$e_{S L}=\beta_{L}^{\prime}=\beta^{*}=\frac{1+\gamma \sigma_{\varepsilon}^{2}}{1+\gamma \sigma_{\varepsilon}^{2}+\lambda \sigma_{\varepsilon}^{2}}, e_{S H}=\beta_{H}^{\prime}=\beta^{* *}=\frac{\theta_{H}-\theta_{L}+1+\gamma \sigma_{\varepsilon}^{2}}{1+\gamma \sigma_{\varepsilon}^{2}+\lambda \sigma_{\varepsilon}^{2}}-\sqrt{\left(\frac{\theta_{H}-\theta_{L}}{1+\gamma \sigma_{\varepsilon}^{2}+\lambda \sigma_{\varepsilon}^{2}}\right)^{2}+\frac{2\left(\theta_{H}-\theta_{L}\right)\left(1+\gamma \sigma_{\varepsilon}^{2}\right)}{\left(1+\gamma \sigma_{\varepsilon}^{2}+\lambda \sigma_{\varepsilon}^{2}\right)^{2}}}$.

First, to make P believe that the project type is "good project", G must distort the optimal risk-sharing contract and bear higher risks. For contract $\left(\alpha_{i}^{\prime}, \beta_{i}^{\prime}\right)$, we can find that $\beta^{*}>\beta_{H}^{\prime}=\beta^{* *}$, which means in order to show that the project is "good project", $\mathrm{G}$ needs to distort the incentive contract $\left(\alpha_{H}, \beta_{H}\right)$ and bear a higher risk $1-\beta_{H}^{\prime}$; on the contrary, for the "bad project" there is no no distortion on the contract, and $\beta_{L}^{\prime}=\beta^{*}$.

Second, ex ante information asymmetry will affect ex post incentive intensity. In our model, the risk allocation will affect the ex post efficiency of the PPP project, and $e(\theta)=\beta(\theta)$. As the proportion of risks borne by $\mathrm{P}$ rises, the effort level rises. In order to show that the project is "good project", the government will bear higher risks, so that $e_{S H}<e_{M H}$. It can be found that compared the Proposition 1, under the separating equilibrium, when the project type is "good project", the incentive intensity of PPP contract reduces.

At the same time, from Equation (11), it can be found that as other hidden information model, the probability distribution of $\theta$ does not affect signal $\left(\alpha_{H}^{\prime}, \beta_{H}^{\prime}\right)$. Only $\Delta \theta=\theta_{H}-\theta_{L}$ will affect the distortion of $\beta_{H}^{\prime}$. $\partial \beta^{* *} / \partial \Delta \theta<0$. With the increase of the uncertainty of $\theta$, the incentive contract will have greater distortion, and the ex post incentive becomes weaker. From Equation (12), we can obtain $t_{H}=0$. Although higher transfer payment is one way of signaling, the signal here is completely composed of the distortion of variable income distribution proportion. The private sector never gets an expected utility greater than zero.

Finally, $\Delta U_{H}=U_{G M}\left(\theta_{H}\right)-U_{G S}\left(\theta_{H}, \theta_{H}\right)$ is recorded as the utility loss brought when the project type is "good project".

$$
\Delta U_{H}=\Delta \theta \beta^{* *}
$$

Because P always gets zero reservation utility, $\Delta U_{H}$ is also social welfare loss, and $\frac{\mathrm{d} \Delta U_{H}}{\mathrm{~d} \Delta \theta}>0$. With the increase of the uncertainty $\Delta \theta$, incentive contract $\left(\alpha_{H}^{\prime}, \beta_{H}^{\prime}\right)$ will gave greater distortion, resulting in greater loss of social/welfare.

In addition to the separating equilibrium when $\tilde{U}_{G M}\left(\theta_{L}\right) \geq I$ and $U_{G S}\left(\theta_{H}, \theta_{H}\right) \geq I$, two other separating equilibriums are worth noting. When $\tilde{U}_{G M}\left(\theta_{L}\right) \geq I$ and $U_{G S}\left(\theta_{H}, \theta_{H}\right)<I$, on the one hand, $G$ has incentive to disguise "bad project" as "good project" and implement; on the other hand, because of excessive incentive distortion in "good project", the government's participation constraint is invalid. In this case, the implementation of "good project" is socially optimal. However, because of the existence of "bad project", "good project" cannot be implemented, so there is the social welfare loss.

When $\tilde{U}_{G M}\left(\theta_{L}\right)<I$ and $\tilde{U}_{G M}\left(\theta_{H}\right) \geq I$, because the participation constraint is invalid, $G$ has no incentive to disguise "bad project" as "good project" and implement. In this case, it is not required to distort the incentive contract of "good project" to distinguish it from "bad project". The contract $\left(\alpha_{i}, \beta_{i}\right)$ will lead to separating equilibrium, and the "bad project" will not be implemented. The good project will cause the effort level of $e=\beta^{*}$. Information asymmetry before the contracting will not affect the incentive intensity $e$.

2) Pooling equilibrium 
In the separating equilibrium discussed above, $G$ sends the signal about the project quality through the state-dependent contract. However, signaling is costly. To prove that the project is "good project", the incentive intensity needs to be distorted. Moreover, the distortion of incentive contract has nothing to do with the prior probability distribution of project type. With the same $\Delta \theta$, the same degree of incentive distortion is always required, even if the project type is very unlikely to be "bad project". As a result, some pooling contract may be acceptable.

In this part, $\mathrm{G}$ issues contract $\left(\alpha^{\prime \prime}, \beta^{\prime \prime}\right)$. In which, $\alpha^{\prime \prime}=\alpha_{H}^{\prime \prime}=\alpha_{L}^{\prime \prime}$ and $\beta^{\prime \prime}=\beta_{H}^{\prime \prime}=\beta_{L}^{\prime \prime}$. P can't update its belief about $\theta$ according to the contract issued by G. Therefore, $\mu\left(\theta_{H} \mid \alpha^{\prime \prime}, \beta^{\prime \prime}\right)=p$. Due to the uncertainty of $\theta, \mathrm{P}$ will ask for additional risk compensation. The optimization problem is as follows.

$$
U_{P P}=\underset{e}{\operatorname{Max}} \alpha+\beta(\bar{\theta}+e)-\frac{1}{2} \lambda \beta^{2} \sigma_{\varepsilon}^{2}-\frac{1}{2} e^{2}-C(\lambda, \beta, p, \Delta \theta)
$$

In which, $C(\lambda, \beta, p, \Delta \theta)=p \beta \Delta \theta+\frac{1}{\lambda} \ln \left(p \mathrm{e}^{-\lambda \beta \Delta \theta}+1-p\right)$, which shows the utility loss brought by the uncertainty of $\theta . \bar{\theta}=p \theta_{H}-(1-p) \theta_{L}$ and $\Delta \theta=\theta_{H}-\theta_{L}$. At the same time, when $\lambda, \beta, p, \Delta \theta, 1-p>0$ (the same below. Without special explanation, these values are assumed to be greater than zero), $C(\lambda, \beta, p, \Delta \theta)$ meets the following conditions. $\frac{\partial C}{\partial \Delta \theta}>0, \frac{\partial^{2} C}{\partial \Delta \theta^{2}}>0, \frac{\partial C}{\partial \beta}>0$ and $\frac{\partial^{2} C}{\partial \beta^{2}}>0$. At this time, we think that $G$ issues contract $\left(\alpha^{\prime \prime}, \beta^{\prime \prime}\right)$ according to the average level of $\theta(\bar{\theta})^{3}$. The optimization problem of $\mathrm{G}$ is as follows.

$$
\begin{aligned}
& \underset{\alpha, \beta, e}{\operatorname{Max}}(1-\beta)(\bar{\theta}+e)-\frac{1}{2} \gamma(1-\beta)^{2} \sigma_{\varepsilon}^{2}-\alpha \\
& \text { s.t. } \quad U_{P P} \geq 0 \\
& \quad e=\beta
\end{aligned}
$$

From (14) and (15), we can obtain:

$$
\begin{gathered}
\beta^{\prime \prime}=\beta=\beta^{* * *}=\frac{1+\gamma \sigma_{\varepsilon}^{2}-C^{\prime}\left(\beta^{* * * * *}\right)}{1+\gamma \sigma_{\varepsilon}^{2}+\lambda \sigma_{\varepsilon}^{2}} \\
\alpha^{\prime \prime}=\alpha=-\beta^{* * *} \bar{\theta}-\frac{1}{2} \beta^{* * * 2}\left(1-\lambda \sigma_{\varepsilon}^{2}\right)+C\left(\beta^{* * * * *}\right)
\end{gathered}
$$

In which, $C^{\prime}(\beta)=\frac{\mathrm{d} C}{\mathrm{~d} \beta}$. We can obtain the expected utility of $\mathrm{G}$.

$$
U_{G P}(\theta)=\theta-\beta(\theta-\bar{\theta})-\frac{1}{2} \gamma \sigma_{\varepsilon}^{2}+\beta\left(1+\gamma \sigma_{\varepsilon}^{2}\right)-\frac{1}{2} \beta^{2}\left(1+\gamma \sigma_{\varepsilon}^{2}+\lambda \sigma_{\varepsilon}^{2}\right)-\frac{1}{2} C(\cdot)
$$

Proposition 3. When $\theta$ and $e$ are uncontractable, $U_{G P}\left(\theta_{L}\right) \geq I$ and $U_{G P}\left(\theta_{H}\right) \geq I$, there is the pooling contract $\left(\alpha^{\prime \prime}, \beta^{\prime \prime}\right)$, so that the equilibrium effort level $e_{S i}(i=L, H)$ is as follows.

$$
e_{P i}=\beta^{\prime \prime}=\beta^{* * *}=\frac{1+\gamma \sigma_{\varepsilon}^{2}-C^{\prime}\left(\beta^{* * *}\right)}{1+\gamma \sigma_{\varepsilon}^{2}+\lambda \sigma_{\varepsilon}^{2}}<\beta^{* *} .
$$

In the pooling equilibrium, there are two kinds of deviation from the incentive contract $\left(\alpha_{i}, \beta_{i}\right)$. On the one hand, fixed transfer payment $\alpha$ is no longer state-dependent. From Equation (18), it can be found that when $\theta=\theta_{H}$ the project value is undervalued, and G pays additional transfer payment $\beta^{\prime \prime}\left(\theta_{H}-\bar{\theta}\right)$; in contrast, when $\theta=\theta_{L}$, the value is overestimated, and transfer payment reduces by $\beta^{\prime \prime}\left(\bar{\theta}-\theta_{L}\right)$. On the other hand, because there is no noiseless signal to distinguish between different projects, private sector are faced with higher uncertainty, and incentive intensity $\beta^{\prime \prime}$ deviates from $\beta^{*} \cdot \frac{\mathrm{d} \beta^{* * *}}{\mathrm{~d} \Delta \theta}<0$ also means that higher degree of uncertainty $\Delta \theta$ will lead to a lower effort level $e_{P i}=\beta^{* * *}$.

\footnotetext{
${ }^{3}$ Similarly, we call the contract under pooling equilibrium as pooling contract.
} 
Similarly to the analysis of the separating equilibrium, we consider the local government's participation constraint. It can be found that, when $U_{G P}\left(\theta_{H}\right)>U_{G S}\left(\theta_{H}, \theta_{H}\right)>I$ and $U_{G P}\left(\theta_{L}\right)>I>U_{G S}\left(\theta_{L}, \theta_{L}\right)$, the value of the project is overvalued when the type is "bad project", the "bad project" which shouldn't have been implemented is implemented by $G$ now. When $U_{G P}\left(\theta_{H}\right)>I>U_{G S}\left(\theta_{H}, \theta_{H}\right)$ and $U_{G P}\left(\theta_{L}\right)>I>U_{G S}\left(\theta_{L}, \theta_{L}\right)$, although the "bad project" which shouldn't have been implemented is implemented under the pooling equilibrium, "good project" that cannot be implemented because of excessive distortion cost can be implemented under separating equilibrium now.

3) Comparison of pooling equilibrium and separating equilibrium

We know that when there are multiple equilibrium, the local government will compare the expected utility under different equilibriums, refer to the belief of the private sector, and choose to issue a contract "showing" the project type or a pooling contract. Therefore, through the comparative analysis on the expected utility of local government under two kinds of equilibriums, we will know which equilibrium will happened.

In the part above, because it is difficult to solve, we didn't obtain the expected utility of local government under the pooling equilibrium $U_{G P}\left(\theta_{i}\right)$ and the value of PPP contract incentive intensity $e_{P i}(i=L, H)$. From Equation (18) and Proposition 3, with the envelope theorem, we can consider the effect of uncertain of $\theta(\Delta \theta)$ on G's expected utility and the total social utility (because $\mathrm{P}$ always get zero expected utility, the social welfare is always equal to G's expected utility).

$$
\begin{gathered}
\frac{\mathrm{d} U_{G P}\left(\theta_{H}\right)}{\mathrm{d} \Delta \theta}=\left.\frac{\partial U_{G P}\left(\theta_{H}\right)}{\partial \Delta \theta}\right|_{\beta=\beta^{* * * *}}=-\beta^{* * * *}(1-p)-\left.\frac{\partial C(\cdot)}{\partial \Delta \theta}\right|_{\beta=\beta^{* * * *}}<0 \\
\frac{\mathrm{d} U_{G P}\left(\theta_{L}\right)}{\mathrm{d} \Delta \theta}=\left.\frac{\partial U_{G P}\left(\theta_{L}\right)}{\partial \Delta \theta}\right|_{\beta=\beta^{*+*}}=\beta^{* * *} p-\left.\frac{\partial C(\cdot)}{\partial \Delta \theta}\right|_{\beta=\beta^{* * * *}}>0
\end{gathered}
$$

On the one hand, we can find that when the project prospect is bad $\mathrm{G}$ always tends to use the contract under the pooling equilibrium $\left(\alpha^{\prime \prime}, \beta^{\prime \prime}\right)$. When the project type is "bad project", due to the increase of uncertainty $\Delta \theta$, G can get more premium $\beta^{* * *} p \Delta \theta$, and $U_{G P}\left(\theta_{L}\right)$ increases. When $\Delta \theta \rightarrow 0$, the contract approach to $\left(\alpha_{L}^{\prime}, \beta_{L}^{\prime}\right)$ and $U_{G P}\left(\theta_{L}\right) \rightarrow U_{G S}\left(\theta_{L}, \theta_{L}\right)$; when $\Delta \theta>0$, it is easy to obtain $U_{G P}\left(\theta_{L}\right)>U_{G S}\left(\theta_{L}, \theta_{L}\right)$. However, whether the local government will issue the pooling contract also depends on whether the local government will choose to issue a contract revealing the project type when the project type is "good project"4.

On the other hand, when uncertainty $\Delta \theta$ is small enough, $\mathrm{G}$ will not send the signal. At this time the possible equilibrium is pooling equilibrium. For the pooling contract $\left(\alpha^{\prime \prime}, \beta^{\prime \prime}\right)$, comparing the expected utility of contract $\left(\alpha_{i}, \beta_{i}\right)$, when the project type is "good project" $\mathrm{G}$ bears double losses, including undervalued project quality $\theta$ and increase of compensation required by $\mathrm{P}$. If $\theta_{H}$ is unchanged, the increase of $\Delta \theta$ will lead to decrease of expected utility. When $\Delta \theta \rightarrow 0$, the contract approaches to $\left(\alpha_{H}, \beta_{H}\right), U_{G P}\left(\theta_{H}\right) \rightarrow U_{G M}\left(\theta_{H}\right)$ and $U_{G S}\left(\theta_{H}, \theta_{H}\right) \rightarrow U_{G M}\left(\theta_{H}\right)$. At this time, however, the increase of $\Delta \theta$ brings different utility losses. $\left.\frac{\partial U_{G P}\left(\theta_{H}\right)}{\partial \Delta \theta}\right|_{\Delta \theta=0}=-\beta^{*}(1-p)$ and $\left.\frac{\partial U_{G S}\left(\theta_{H}, \theta_{H}\right)}{\partial \Delta \theta}\right|_{\Delta \theta=0}=-\beta^{*}$. Therefore, when $\Delta \theta$ is small enough, com-

Pared to separating equilibrium, $\mathrm{G}$ will get higher expected utility under the pooling equilibrium, and $\mathrm{G}$ tends not to send signal. The results are relatively consistent with the intuition. $\Delta \theta \rightarrow 0$ means that the influence of uncertainty on the cooperation between both parties is small enough. The benefits of distinguishing between different project types are not big enough, and it is beneficial to accept a pooling contract. However, when $\Delta \theta \gg 0$, the direction of inequality changes with parameters. This means that it is difficult to determine whether $\mathrm{G}$ sends the signal when the project prospect is relatively good.

In fact, under the given parameters, when the project has good prospect ("good project"), whether the local government has incentive to issue the contract $\left(\alpha_{H}^{\prime}, \beta_{H}^{\prime}\right)$ determines the type of equilibrium. When parameters make $U_{G S}\left(\theta_{H}, \theta_{H}\right)>U_{G P}\left(\theta_{H}\right)$, G has incentive to send the signal. At this time we think that the pooling equilibrium violating the "intuitive criterion" and shall be removed. At this time the reasonable equilibrium is separating equilibrium. On the contrary, when parameters make $U_{G S}\left(\theta_{H}, \theta_{H}\right)<U_{G P}\left(\theta_{H}\right)$, G has incentive to send the signal. We think that the pooling equilibrium complies with the "intuitive criterion". At this time the rea-

${ }^{4}$ Under the given parameter, if the project type is “good project”, G chooses to issue a signaling contract $\left(\alpha_{H}^{\prime}, \beta_{H}^{\prime}\right)$. When the project type is "bad project", $\mathrm{G}$ can only choose to issue contract $\left(\alpha_{L}^{\prime}, \beta_{L}^{\prime}\right) .\left(\alpha_{L}^{\prime \prime}, \beta_{L}^{\prime \prime}\right)$ won't be accepted by the private sector, because participation constraints of $\mathrm{P}$ is invalid. 
sonable equilibrium is pooling equilibrium.

\section{Conclusions}

This article considers the PPP contracts with privately informed local governments. Before the start of the project, the local government has more precise information about the project prospect (project quality) than private partners. In this case, the local government has incentive to use its information advantage for the PPP project, and gain profit by hiding adverse information. When the project has poor prospect ("bad project"), the local government has the incentive to report the wrong project type, leading to losses of PPP participants. In order to get the trust of PPP participants, a signaling contract may be chosen by the local government. The contract revealing a good project prospect ("good project") requires that the government bears more risks than the project with poor prospect ("bad project"). And in our model, the private sector's effort level in the construction stage $e$ is related to the allocation proportion $\beta$ of the revenue $R$. Under the separating equilibrium, project with good prospect ("good project") can be identified by the private sector. The cost is reduced incentive intensity of project with good prospect ("good project") ex post.

When local government's participation constraint is under consideration, it can be found that the PPP project, whose revenue is lower than its investment, will always not be implemented under the effective signaling. However, the value of project with good prospect ("good project") may be lower than the investment due to incentive distortion brought by signaling, and the project cannot be implemented.

We can also see that a signaling contract is not always beneficial. In some cases, for example $\Delta \theta$ or $1-p$ is small enough, the efficiency distortion brought by signaling is greater than the additional risk compensation needed in the pooling circumstances, and a pooling contract is superior to the separating contract. However, it is important to note that whether the pooling equilibrium or separating equilibrium exists relies on the belief of private sector. If the private sector believes that the local government always chooses to send the signal of project quality, there will be no pooling equilibrium, and the local government will bear high signaling cost.

Under pooling equilibrium, project with poor prospect ("bad project”), whose revenue is lower than its investment, may be implemented. On the other hand, projects that cannot be implemented under the separating equilibrium (because of high signaling cost) can be implemented under the pooling equilibrium sometime.

Which equilibrium will be happen is uncertain. The result depends on whether local government has incentive to abandon "pooling" contract $\left(\alpha^{\prime \prime}, \beta^{\prime \prime}\right)$ and choose to send the project type information if the project has good prospect ("good project"). When the local government has incentive to reveal the type of the project when the project type is "good project", the separating equilibrium is the reasonable equilibrium. On the contrary, if pooling contract leads to higher expected utility of local government than the separated contract does when the project has good prospect, the pooling equilibrium is the reasonable equilibrium.

\section{References}

[1] Hart, O. (2003) Incomplete Contracts and Public Ownership: Remarks, and an Application to Public-Private Partnerships. The Economic Journal, 113, C69-C76. http://dx.doi.org/10.1111/1468-0297.00119

[2] Martimort, D. and Pouyet, J. (2008) To Build or Not to Build: Normative and Positive Theories of Public-Private Partnerships. International Journal of Industrial Organization, 26, 393-411. http://dx.doi.org/10.1016/j.ijindorg.2006.10.004

[3] Iossa, E. and Martimort, D. (2012) Risk Allocation and the Costs and Benefits of Public-Private Partnerships. The RAND Journal of Economics, 43, 442-474. http://dx.doi.org/10.1111/j.1756-2171.2012.00181.x

[4] Iossa, E. and Martimort, D. (2014) Corruption in Public-Private Partnerships, Incentives and Contract Incompleteness. DICE Report, 12, 14.

[5] De Bettignies, J.E. and Ross, T.W. (2009) Public-Private Partnerships and the Privatization of Financing: An Incomplete Contracts Approach. International Journal of Industrial Organization, 27, 358-368. http://dx.doi.org/10.1016/j.ijindorg.2008.10.004

[6] Engel, E., Fischer, R. and Galetovic, A. (2013) The Basic Public Finance of Public-Private Partnerships. Journal of the European Economic Association, 11, 83-111. http://dx.doi.org/10.1016/j.ijindorg.2008.10.004 